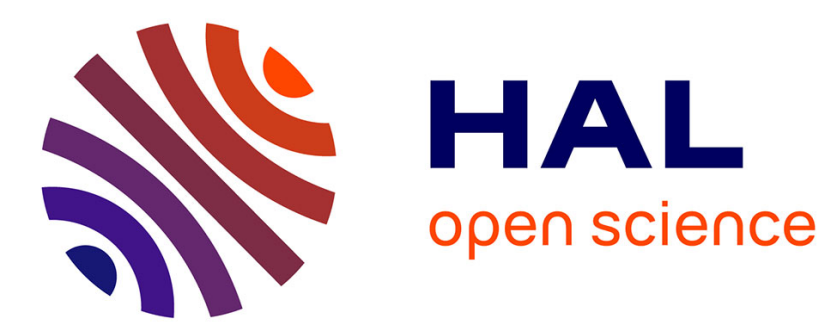

\title{
Unexpected predominance of wine grower location over soil trafficability for vine management in southern France
}

Anne Biarnès, Guillaume Coulouma, Claude Compagnone

\section{To cite this version:}

Anne Biarnès, Guillaume Coulouma, Claude Compagnone. Unexpected predominance of wine grower location over soil trafficability for vine management in southern France. Agronomy for Sustainable Development, 2012, 32 (3), pp.661-671. 10.1007/s13593-011-0052-y . hal-00930527

\section{HAL Id: hal-00930527 \\ https://hal.science/hal-00930527}

Submitted on 1 Jan 2012

HAL is a multi-disciplinary open access archive for the deposit and dissemination of scientific research documents, whether they are published or not. The documents may come from teaching and research institutions in France or abroad, or from public or private research centers.
L'archive ouverte pluridisciplinaire HAL, est destinée au dépôt et à la diffusion de documents scientifiques de niveau recherche, publiés ou non, émanant des établissements d'enseignement et de recherche français ou étrangers, des laboratoires publics ou privés. 


\title{
Unexpected predominance of wine grower location over soil trafficability for vine management in southern France
}

\author{
Anne Biarnès • Guillaume Coulouma • \\ Claude Compagnone
}

Accepted: 26 July 2011 /Published online: 19 October 2011

(C) INRA and Springer-Verlag, France 2011

\begin{abstract}
On a regional scale, many management concerns, such as agricultural planning and water contamination management, require information regarding the diversity and location of agricultural practices. One means of obtaining this information is to search for spatially explicit indicators that correspond to factors that drive agricultural practices. The objective of our study was to assess the role of soil trafficability on the distribution of soil surface management practices in a Mediterranean vine-growing region characterised by water contamination by herbicides. Soil surface management relies on different combinations of technologies such as shallow tillage, chemical weeding, and grass cover. We hypothesised that soils characterised by low trafficability were associated with the use of chemical weeding or grass cover in alleys that tractors use while spraying pesticides. Here, data on practices were collected by survey at the plot resolution. Soil trafficability was evaluated based on an expert classification of the soil units of a 1:25,000 soil map. Using classification trees, we tested the ability of the following three explanatory variables to determine the choice of practice: (1) the trafficability of the
\end{abstract}

\footnotetext{
A. Biarnès $(\bowtie)$

IRD, UMR Lisah INRA-IRD-SupAgro,

2 place Viala,

34060 Montpellier, France

e-mail: biarnes@supagro.inra.fr

G. Coulouma

INRA, UMR Lisah INRA-IRD-SupAgro,

2 place Viala,

34060 Montpellier, France

C. Compagnone

AgroSup Dijon, UR Listo INRA,

26 bd Dr Petitjean,

21079 Dijon Cedex, France
}

plot, (2) the percentage of plots with low trafficability within the vineyard of the farm holding, and (3) the wine grower residence place. Our results show that the trafficability classifies $59 \%$ of plots. The percentage of plots with low trafficability classifies $76 \%$ of plots. The wine grower residence place classifies $84 \%$ of the plots. Although the choice of practice correlated with soil trafficability, the residence place of the wine grower unexpectedly overdetermined the practice choice. As a consequence, our findings evidence a spatial variability of the role of soil in the distribution of soil surface management practices. In addition, soil trafficability cannot be used as major indicator of the practice spatial distribution.

Keywords Viticulture · Herbicide pollution · Soil surface management practice $\cdot$ Soil trafficability $\cdot$ Expert soil classification $\cdot$ Classification tree

\section{Introduction}

On a regional scale, many management issues are related to the nature, diversity and location of cropping systems. For example, agricultural planning or assessment of farmers' or traders' marketing decisions requires information that allows us to predict forage or crop yields on a national or regional scale (Yun 2003). Estimating the degree of pesticide pollution in streams or groundwater requires accurate knowledge of pesticide use and agricultural practices that influence surface water runoff or infiltration at the scale of the catchment or river basin (Louchart et al. 2001). Consequently, information regarding crops and agricultural practices on a regional scale is required to address many agri-environmental problems. However, agricultural inventories generally provide only partial data 
on cropping systems, and exhaustive ground surveys or enquiries are clearly unrealistic at a regional scale. Therefore, methods that aim to map the variability of agricultural practices have been inventoried (Leenhardt et al. 2010). One of these methods is the search for spatially explicit indicators that correspond to cropping systems' driving factors; these indicators can be used to predict and map the spatial variation of those cropping systems.

Because soil supports crops, it is a good candidate indicator of the spatial distribution of cropping systems. Soil supports root systems, provides all or part of a crop's mineral nutrients and stores water. However, soil also places limitations and constraints on farmers that restrict the range of possible crops or crop management systems. For example, a possible restriction is soil trafficability, which is defined as the ability of soil to support traffic without being damaged (Paul and Devries 1979; Rounsevell and Jones 1993; Droogers et al. 1996) or as the ability of soil to provide adequate traction for tractors (Earl 1997). Rounsevell and Jones (1993) showed that soil trafficability may restrict the range of technical operations or the number of workable days for completing these operations.

As a consequence of the opportunities and constraints soil conditions open for or place on cropping systems, soil is often a focal point in land-use planning. For example, the FAO Framework for Land Evaluation (FAO 1976), which is the primary procedure used worldwide in local, regional and national land-use planning, is based mainly on land quality selection (Manna et al. 2009). However, little attention has been devoted to the relationship between soil characteristics and current crop management systems, particularly on a regional scale. Most of the literature concerning the relationship between soil and agricultural practices has not described the influence of soil diversity on farming practices but rather focused on (1) analysing the impact of current practices on soil characteristics or functions and (2) identifying more sustainable practices (Lal 2009; Mueller et al. 2010). Ethnopedologic approaches that aim to describe local soil knowledge sometimes lead to detailed analyses of the relationships between soils and current land management practices (Desbiez et al. 2004). Most of the time, however, these studies are conducted on a local spatial scale, and the village scale is the preferred level of study (Barrera-Bassols and Zinck 2003).

The objective of this paper was to evaluate the role of soil trafficability in the distribution of soil surface management practices in a French Mediterranean vine-growing region characterised by a wide range of different soils. Knowledge of the diversity and spatial distribution of soil surface management practices in this region is required to evaluate the practices' impact on surface water fluxes and herbicide pollution. Studies have shown that surface water contamination is related to herbicide leaching through runoff during heavy rainfall (Louchart et al. 2001). In vineyards, soil surface management practices play a crucial role in pollution because they determine both the type and amount of herbicide applied and the evolution of soil surface characteristics, which influence surface runoff (Paré et al. 2011). These practices rely on different combinations of three well-known technologies (shallow tillage, chemical weeding and grass cover). Each technology has a different effect on soil trafficability after rainfall and, consequently, the number of workable days for spraying pesticides during the spring and early summer. We hypothesised that soils characterised by low trafficability are associated with combinations of technology that aim to preserve soil trafficability after rainfall in the alleys through which tractors pass to spray pesticides.

Statistical relations between soil surface management practices and soil trafficability were assessed using classification trees (Breiman et al. 1984). Based on the results of a previous study (Biarnès et al. 2009), we hypothesised that the choice of the studied practices may be related not only to plot scale characteristics but also to characteristics of the territory of the farm holding and that relationships between soil and soil surface management may vary according to the local environments of the wine growers. Consequently, three variables were tested and compared: the trafficability of the plot, an indicator of soil trafficability at the scale of the holding and the place of residence of the wine grower.

\section{Materials and methods}

\subsection{Study site}

The study area was the Peyne River Valley in the LanguedocRoussillon region of southern France, which is one of the largest wine-producing regions in the world (Fig. 1). It covers an area of $75 \mathrm{~km}^{2}$. In terms of physical characteristics, the study area is part of the main vineyard landscape of southern Languedoc-Roussillon, which developed on top of Miocene marine deposits. The altitude ranges from $20 \mathrm{~m}$ (south eastern region of the study area) to $340 \mathrm{~m}$ (north western region of the study area). There are sharp contrasts between the northwest region, which is rugged and mainly scrubcovered, with little arable land, and the rest of the valley, which has gentler landforms and is almost entirely covered by vineyards.

The soil pattern of the Peyne River Valley arises mainly from variations in lithology (Coulouma 2008), and the main soil characteristics depend on the type of parent material. The entire valley is underlain by heterogeneous Miocene marine and lacustrine sediments, such as marl, limestone and calcareous sandstone, which form the parent material of 
Fig. 1 Location of the study area
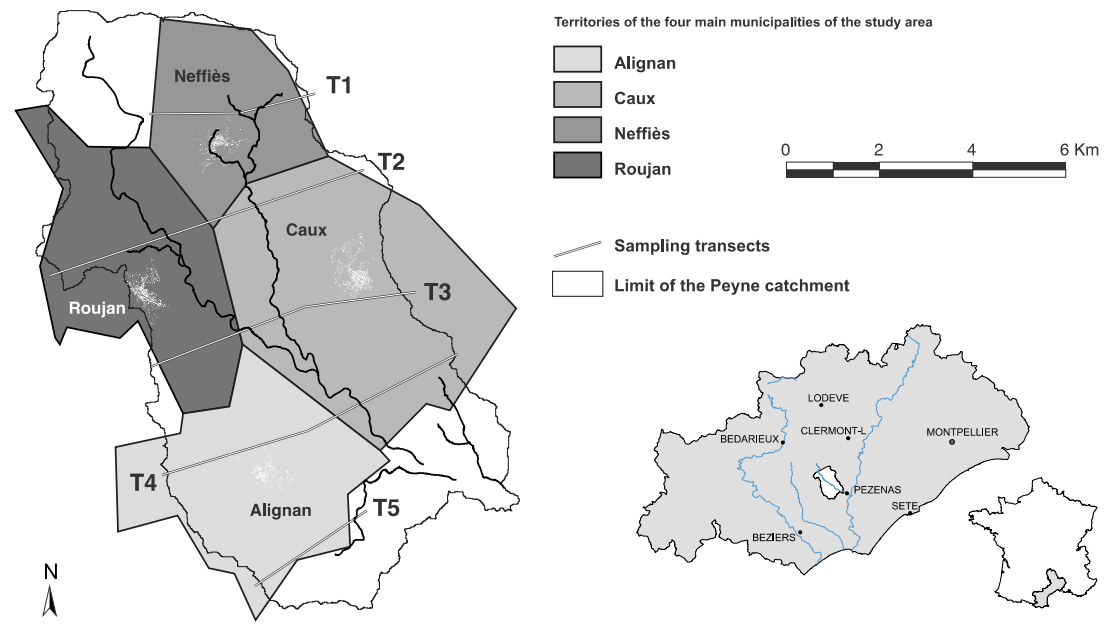

several types of soil, including calcaric leptosols, calcaric regosols and calcisols (IUSS Working Group WRB 2006). These Miocene sediments are partly overlain by successive alluvial deposits ranging from Pliocene to Holocene, and they differ in their initial nature and in the duration of weathering conditions. Thus, these sediments have produced an intricate soil pattern that includes a great range of soil types, such as calcisols, endogleyic calcisols, luvisols (chromic) and fluvisols. Recent volcanic activity and local transport of colluvial material along slopes have added to the complexity of the soil pattern. Consequently, the soils of the valley present contrasting characteristics in terms of the texture and stoniness of the soil layers, which determine the soils' mechanical properties and, in particular, their trafficability after rainfall. Clay content ranges from 100 to $550 \mathrm{~g} \mathrm{~kg}^{-1}$ in the tilled layers. Several of the soils have a high proportion of pebbles ( $>40 \%$ of the topsoil), while other soils do not have any pebbles. Low trafficability of several of the soils in the valley after rainfall is known to be a problem for wine growers, particularly during the spring and early summer, because low trafficability makes it difficult for tractors to pass to spray pesticides. Thus, during rainy years, low trafficability may reduce the number of workable days for conducting repeated sprayings.

The Peyne River Valley intersects the territories of various municipalities. In 2000, according to data from the most recent farm census carried out by the Regional Direction of Agriculture and Forest, 442 vine-growing farm holdings were registered in the four main municipalities of the valley (Alignan, Caux, Neffiès and Roujan), which cultivated 3,310 ha of vines in total. Fifty-nine percent of the farm holdings cultivated less than 5 ha of vines, and only $11 \%$ of the farm holdings cultivated over 20 ha of vines. In terms of area, the former farm holdings represented only $13 \%$ of the vineyard area, and the latter farm holdings represented $43 \%$.

Like many other vineyard areas, the Peyne River Valley suffers from serious surface water contamination by herbicides.

\subsection{Data}

The database included 491 wide alley vine plots and the five variables presented in Table 1: the variable to be explained (the soil surface management practice), three potential explanatory variables (the class of soil trafficability of the plot, the percentage of plots that are classified as having low soil trafficability within the set of wide alley vine plots of the farm holding (Farm LST) and the place of residence of the wine grower) and an additional variable (the municipality of the location of the plot) that was used to analyse the spatial variability of the results.

\subsubsection{Soil surface management practices}

In the South of France, soil surface management practices in vineyards are based on three well-known technologies: shallow tillage, chemical weeding and permanent (natural or sown) grass cover controlled by mowers or rotary cutters. These technologies allow for the control of weed pressure but may have other objectives. For example, chemical weeding or grass cover reduces the risk of low trafficability of soil after rainfall. Due to the spatial organisation of vine plots in rows, wine growers can adapt soil surface management practices to various types of rows (vine strip and different types of alleys) and thus combine different technologies within a single plot.

Data on soil surface management practices in the Peyne River Valley were obtained for the 2003-2004 agricultural year. The data were gathered by surveying wine growers based in the four main municipalities of the Valley. Forty-five wine growers were randomly selected by sampling forty-five vine plots along five transects perpendicular to the Peyne River (Fig. 1). The transects were evenly spread upstream and downstream to allow for an intersection of municipalities and soil units. The wine growers cultivating these plots were 
Table 1 Collected variables

Soil surface management practice

Soil trafficability of the plot

Farm LST: percentage of plots with low soil trafficability

within the set of wide alley vine plots of the farm holding

Place of residence of the wine grower

Municipality of location of the plot
$\mathrm{P} 1, \mathrm{P} 2, \mathrm{P} 3$

High, indeterminate, low

$0 \%$ to $80 \%$

Alignan, Caux, Neffiès, Roujan

Alignan, Caux, Neffiès, Roujan

The municipality of a plot may be different from the place of residence of the wine grower who cultivates it

contacted by telephone to make appointments for interviews, which were conducted at their residences. The survey questionnaire focused on the soil surface management technologies used in each plot cultivated by the selected wine growers. In addition, the row spacing of each plot was noted, and each plot was precisely located on a land register map so that it could be assigned to a class of soil trafficability and a municipality.

From the total surveyed plots, a sample of 491 vine plots covering 535 ha were selected in a two-step procedure. In the first step, the plots characterised by alleys with a width less than $1.8 \mathrm{~m}$ were excluded because their soil surface management practice is already well known. A previous study (Biarnès et al. 2009) has shown that these vine plots are principally associated with chemical weeding and manual herbicide spraying because it is difficult for tractors to pass through narrow alleys. In the second step, to allow for the calculation of the percentage of wide alley plots with low trafficability in the vineyards of each farm holding, we considered only the plots that belonged to 27 of the 45 wine growers interviewed. The selected wine growers had the totality of their vine plots located on the 1:25,000 soil map of the Peyne River Valley reported by Coulouma (2008). Each grower cultivated at least 6 ha of wide alley plots of vine and at most 50 ha distributed among various plots (at least nine).

To test our hypothesis that soils characterised by low trafficability are associated with combinations of technology that aim to preserve soil trafficability after rainfall in the alleys where tractors pass to spray pesticides, the practices were differentiated into three types. In practice P1, the alleys were systematically and repeatedly shallow-tilled at least twice a year and at most five or six times a year. In practice P2, several of plot's alleys were managed by shallow tillage, but these alternated at regular intervals with alleys managed by either chemical weed control (P2a) or permanent grass cover (natural grass or sown grass) controlled by mowers or rotary cutters (P2b). The untilled alleys, located every two, three or four alleys, allowed tractors to pass more easily after rainfall to spray pesticides. Finally, practice P3 was based on chemical weeding alone, and the alleys were never or rarely tilled (once a year at most).
As a trend, the risk of runoff and herbicide leaching that these practices generate can be ranked as follows: $\mathrm{P} 2 \mathrm{~b}<\mathrm{P} 1<$ $\mathrm{P} 2 \mathrm{a}<\mathrm{P} 3$. From P2b to P3, the environmental risk increases due to an increase in herbicide used (from partial to total chemical weed control) and an increase in the use of technologies that favour surface runoff. Although they did not generate the same environmental risks, practices $\mathrm{P} 2 \mathrm{a}$ and $\mathrm{P} 2 \mathrm{~b}$ were grouped together for the analysis because we hypothesised that both practices are chosen to resolve soil trafficability problems and the determinant of the choice between P2a and P2b was already known. A previous study using the same data (Biarnès et al. 2009) showed that the choice between P2a and P2b was related to the economic scale of the farm holding and that there was a tendency to choose $\mathrm{P} 2 \mathrm{~b}$ when the economic scale increased.

\subsubsection{Soil trafficability}

To map differences in soil trafficability in the Peyne River Valley, soil properties were determined using the 1:25,000 soil map of the Peyne River Valley created by Coulouma (2008). This soil map describes different types of soil and delimits their spatial variability. A total of 42 soil units are defined: 35 homogeneous soil units and 7 complex soil units. Each homogeneous soil unit is characterised by one type of soil, and the complex soil units includes different types of soil at the plot scale. However, because soil properties can vary within each type, expert knowledge is needed to identify the main soil properties that influence soil trafficability for that type. In this way, a three-class expert classification of trafficability was carried out for high, low and indeterminate trafficability (Fig. 2).

In the case of the homogeneous soil units, the expert soil trafficability classification was based on a combination of four variables, and the values for each soil unit on the map were assessed according to the main soil properties of that unit. Soil trafficability directly depends on the pressure applied to the topsoil by tractor wheeling and on soil strength. The applied pressure was considered homogeneous within the study area because the same types of tires and tractors were used by all of the farmers in the Peyne 


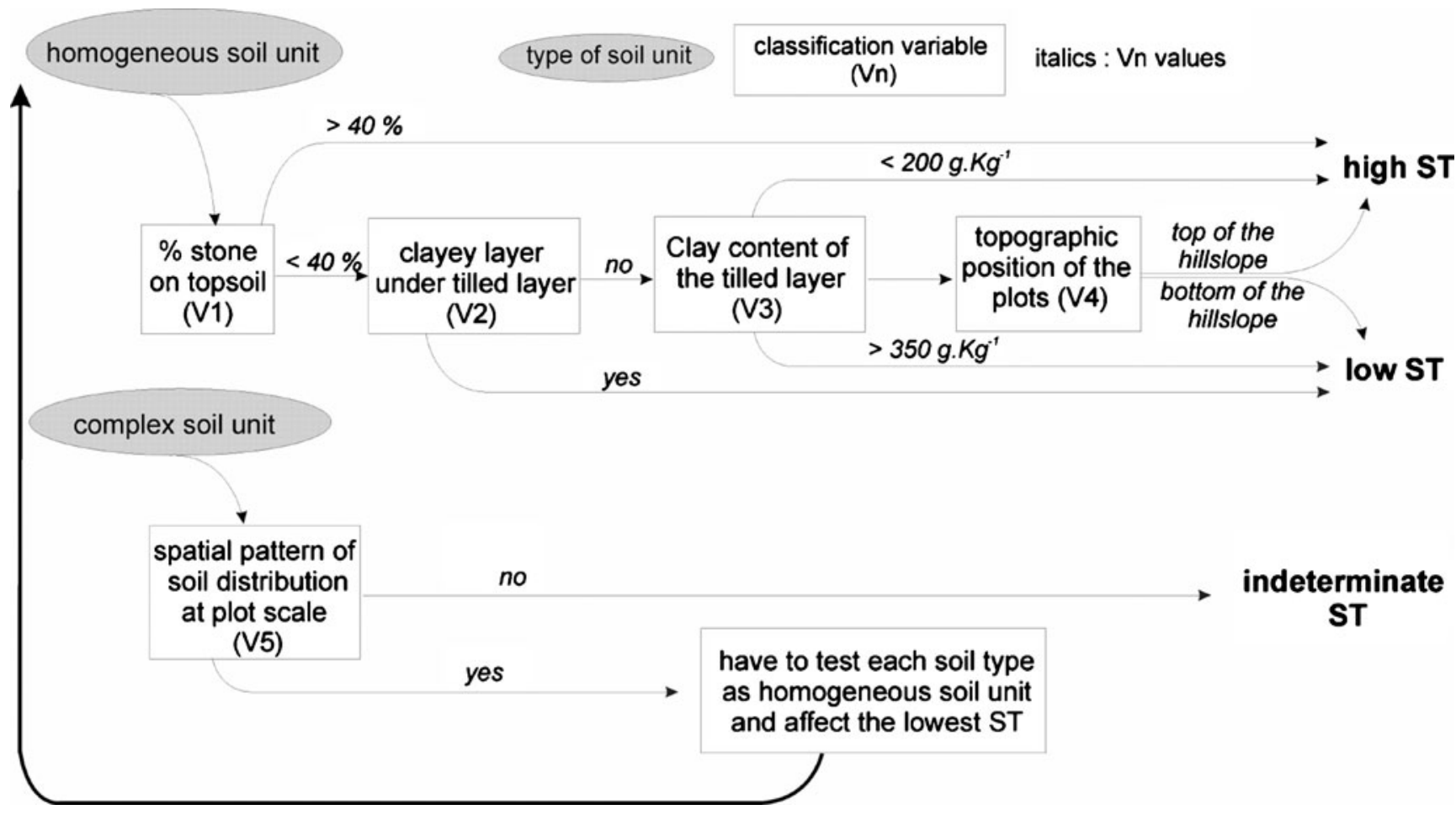

Fig. 2 Expert classification of soil trafficability $(S T)$ according to characteristics of the soil units

Valley. Thus, the applied pressure was not considered for the trafficability classification. According to the literature, soil strength depends on soil water content and permanent soil properties (Horn and Fleige 2003). Texture and the presence of coarse fragments in tilled horizons were considered the predominant influences on soil strength in the case of the Mediterranean vineyards. Organic carbon content was not considered because it was consistently very low. In the case of vines, tilled horizons correspond to a deeply tilled soil layer, i.e., a soil layer that has been deeply ploughed just prior to the establishment of the vineyard (Coulouma et al. 2006). The first variable of the classification (V1) relates to the stone content in the deeply tilled layer (more than 40\%), which dramatically increases soil strength. The three other variables are related to the soil water content in the tilled layer. V2 relates to the texture of the soil under the deeply tilled layer. A heavy clayey layer with low hydraulic conductivity beneath the tilled layer produces a higher soil water content in the tilled layer. At the scale of the soil unit, the soil water content also depends on the texture of the tilled layer (V3) and the main topographic position of the plots (V4) in the soil unit, which indicates the specific contributing hydrological area (Brocca et al. 2007).

In the case of complex soil units, an additional parameter was considered: the existence of a well-known spatial pattern of soil distribution at the plot scale (V5). For example, soils developed from Miocene sediments vary within terraced hillslopes at the plot scale. At the top of the toposequence, soils are shallower (due to erosion) and sandier than at the bottom (due to deposition). In our study, when such a pattern existed, a class of soil trafficability was first assessed for each existing soil type according to the previous rules of classification. The lower class of trafficability was then assigned to the entire soil map unit. Moreover, if a well-known spatial pattern did not exist, the indeterminate class was assigned.

Using the obtained soil trafficability map, a class of trafficability was assigned to each of the 491 surveyed vine plots obtained by a GIS spatial operation. If a single class of trafficability represented most of the plot area (more than $70 \%$ ), the entire plot was assigned to that particular class of soil trafficability. However, if the plot area was not dominated by a single class of soil trafficability, then the lowest representative class of soil trafficability (low < indeterminate $<$ high) was assigned to the plot. The percentage of wide alley plots with low trafficability within the vineyards of the farm holdings was then computed.

\subsection{Data processing}

Data processing was based on the tree classification (CART) algorithm (Breiman et al. 1984). The CART algorithm is very popular because it facilitates classification model interpretation. It is based on a recursive partitioning process of the multidimensional space defined by a set of explanatory variables in areas that are as homogeneous as possible 
regarding the variable being explained (the soil surface management type in our case). The result is a binary hierarchical tree. The tree is characterised by several splits whose nodes depend on homogeneity measures (the Gini index in our case), which determine a set of logical if-then conditions linking the variable to be explained to the explanatory variables. Each terminal node is assigned the label of the majority class (practices $\mathrm{P} 1, \mathrm{P} 2$ or $\mathrm{P} 3$ in this study). The classification process starts at the root node (which encompasses the entire dataset) and ends at the terminal nodes. Classification trees are usually pruned to avoid over-fitting, i.e., making them too sensitive to variations specific to the datasets used for model building. To maintain robust and interpretable trees, we chose to prune them very short by progressively reducing the number of required nodes until an easily interpretable tree was produced.

To compare the performance of the three tested explanatory variables in classifying the practices, three trees were built by adding individual variables: tree $\mathrm{T} 1$ was built using the first variable, tree T2 was built using the two first variables and tree $\mathrm{T} 3$ was built using all three variables. The respective performances of the trees were compared based on the rate of misclassification when each plot was classified according to the majority practice of the node to which it belonged. The comparison was based on a global misclassification rate computed on the basis of the total sample of plots and on four local misclassification rates, each computed on the basis of the sub-sample of plots located in the same municipality (Alignan, Caux, Neffiès or Roujan). These local misclassification rates were computed to reveal the possible spatial variability of the misclassification rates.

To facilitate the interpretation of tree T3, the existence of an effect of the wine grower's place of residence on the distribution of the practice-trafficability pairs at the plot scale was tested by a Pearson's chi-square test and by the calculation of Pearson residuals. The main objective was to verify that the combination P2-low soil trafficability was independent of the place of residence.
All of these methods were conducted on R 2.6.0 statistical software using the tree package (Ripley 2007) and custom R scripts.

\section{Results and discussion}

3.1 Distribution of soil surface management practices and soil trafficability in the plot sample

The distribution of soil surface management practices in the total sample of vine plots and farm holdings is summarised in Table 2. Shallow tillage (P1) and mixed practices (P2) were the most common practices. These practices were used in over $96 \%$ of the studied area. In contrast, chemical weeding (P3) was used only in a very small area.

The distribution of the three classes of soil trafficability within the surveyed plots is presented in Table 3. The distribution of trafficability in the sample plots is representative of the distribution of trafficability in the total vineyard area of Peyne Valley. High soil trafficability was the dominant class of soil trafficability, but low trafficability made up almost one third of both the surveyed plots and the vineyard area of Peyne Valley.

Mapping the types of practices in the area according to the geographic coordinates of the surveyed plots clearly shows that soil surface management practices were not randomly distributed in the area (Fig. 3a). P2 was the dominant practice in the municipalities of Roujan and Alignan (85\% and 57\% of the surveyed plots located in these municipalities, respectively), and $\mathrm{P} 1$ was the dominant practice in the municipalities of Caux and Neffiès $(81 \%$ and $78 \%$ of the plots, respectively). Moreover, soil trafficability was also unequally distributed in the study area, and low trafficability was represented more in the southern part of the valley than in the northern part (Fig. 3b). Low trafficability was the dominant class in the municipality of Alignan but not in the other municipalities. These distributions of practices and soil trafficability are difficult to visually compare, but they show that the relationship between soil trafficability and soil surface management practices varied spatially.

Table 2 Distribution of soil surface management practices in the sample plots and farm holdings

\begin{tabular}{|c|c|c|c|c|c|c|c|c|}
\hline \multirow[t]{2}{*}{ Soil surface management practice } & \multicolumn{2}{|c|}{ Plots concerned } & \multicolumn{2}{|c|}{ Land area concerned } & \multicolumn{2}{|c|}{ Farm holdings concerned } & \multicolumn{2}{|c|}{$\begin{array}{l}\text { Farm holdings predominantly } \\
\text { using this type of practice }\end{array}$} \\
\hline & Number & $\%$ & $\mathrm{Ha}$ & $\%$ & Number & $\%$ & Number & $\%$ \\
\hline $\mathrm{P} 1$ & 251 & 51 & 276 & 51 & 20 & 74 & 12 & 44 \\
\hline $\mathrm{P} 2$ & 218 & 44 & 240 & 45 & 18 & 67 & 14 & 52 \\
\hline P3 & 22 & 5 & 19 & 4 & 6 & 22 & 1 & 4 \\
\hline
\end{tabular}

Most of the wine growers used various practices but had one that predominated 
Table 3 Distribution of soil trafficability in the sample plots and vineyard area of the study site

\begin{tabular}{llllllll}
\hline \multirow{2}{*}{ Soil trafficability } & \multicolumn{3}{l}{ Sample of surveyed plots } & & \multicolumn{2}{c}{ Vineyard area of Peyne Valley } \\
\cline { 2 - 4 } & Number & $\%$ & Ha & $\%$ & & Ha & $\%$ \\
\hline High & 260 & 53 & 278 & 52 & 1673 & 56 \\
Low & 147 & 30 & 155 & 29 & 926 & 31 \\
Indeterminate & 83 & 17 & 102 & 19 & 388 & 13 \\
\hline
\end{tabular}

\subsection{Performances of the explanatory variables} used to classify the practices

Figure 4 presents the three selected trees (T1, T2, T3), and Table 4 shows the misclassification rates obtained for each tree. As shown in Fig. 4, the three tested variables enabled soil surface management practices to be classified as P1 or P2. Practice P3 was not distinguished because, in our sample of surveyed plots, the number of plots under P3 was too small compared to the numbers of plots under $\mathrm{P} 1$ or $\mathrm{P} 2$.

Tree $\mathrm{T} 1$ shows that soil surface management practices were significantly linked to plot trafficability. The plots characterised by low soil trafficability (the right branch of the tree) were assigned to practice $\mathrm{P} 2$, while the plots characterised by high or indeterminate trafficability were assigned to practice P1 (the left branch of the tree). However, the misclassification rate computed for the whole study site was high (0.42, as seen in Table 4$)$ and unevenly distributed in space. The standard deviation of the local misclassification rates was 0.16 . The plots located in Alignan and, particularly, those located in Roujan were very poorly classified (the misclassification rates were valued at 0.47 and 0.62 , respectively).
As shown in tree $\mathrm{T} 2$, when the second variable is introduced (Farm LST), it takes precedence over the first. Plots cultivated in farm holdings that exceeded a threshold value of $35.4 \%$ of wide alley plots with low trafficability were assigned to practice $\mathrm{P} 2$; those cultivated in farm holdings under this threshold value were assigned to P1. T2 significantly improved the good classification of the plots: only $24 \%$ of plots were misclassified. Improvement was seen for all four municipalities, but the differences between municipalities remained high (standard deviation=0.17), with plots located in Roujan remaining mostly misclassified (51\% of plots).

Tree T3 was constructed by adding the variable "place of residence of the wine grower" to the two other variables but kept only the new variable. This new variable alone captured most of the variability in choice of practice. Like the other two trees, T3 had only two branches. The right branch associated practice P1 with wine growers living in Caux or Neffiès. The left branch associated P2 with wine growers living Alignan or Roujan. With a global misclassification rate of 0.16 , this tree was the one that best classified the practices. Moreover, the classification errors were relatively well distributed among the four municipalities ( standard deviation $=0.04$ ).
Fig. 3 Spatial distribution of soil surface management practices and soil trafficability in the study site with uneven distributions of (A) soil surface management practices and (B) soil trafficability

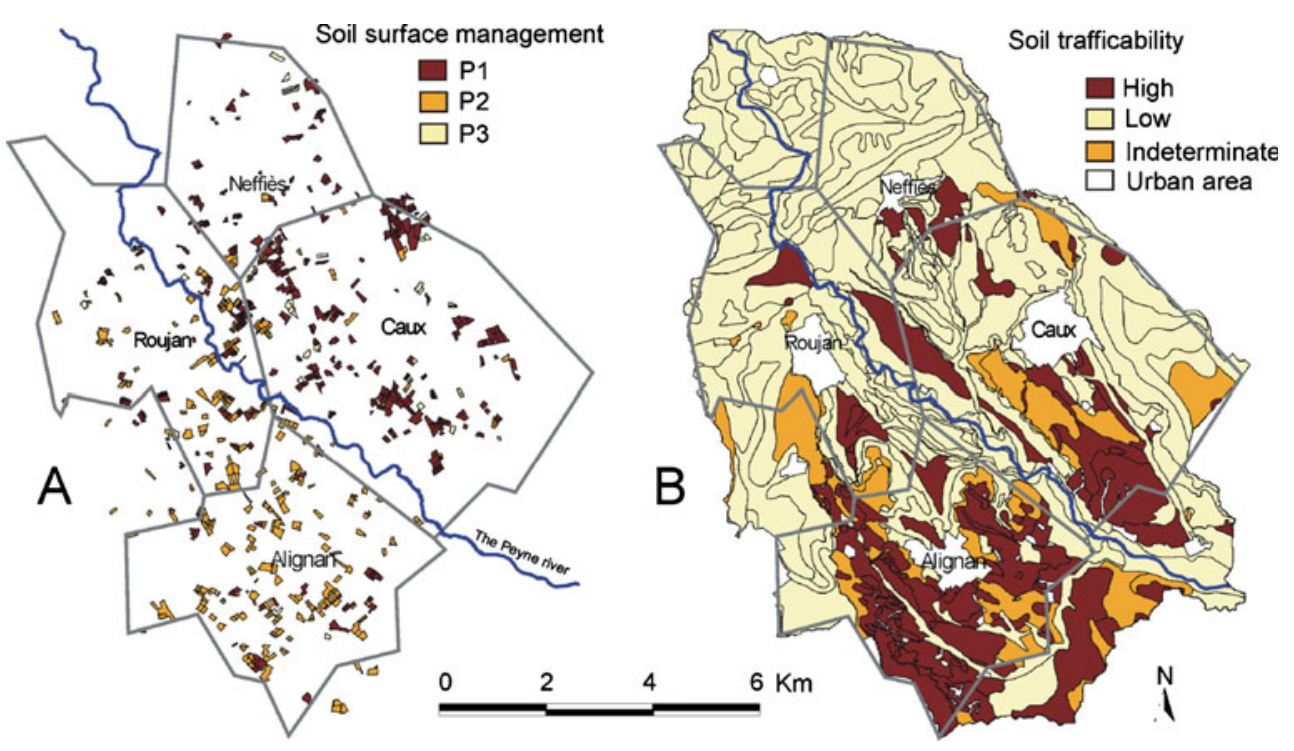




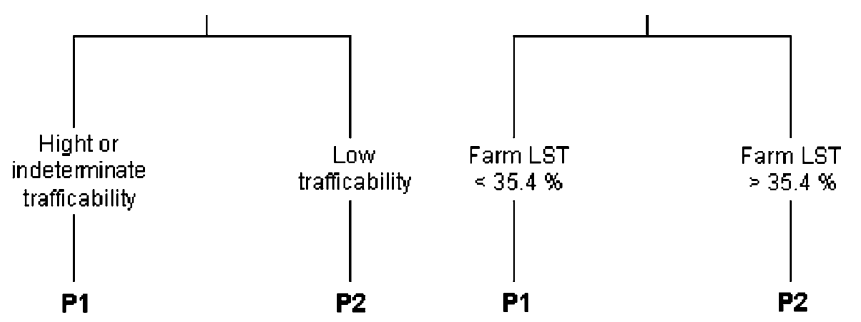

Tree T1

Tree $\mathrm{T} 2$

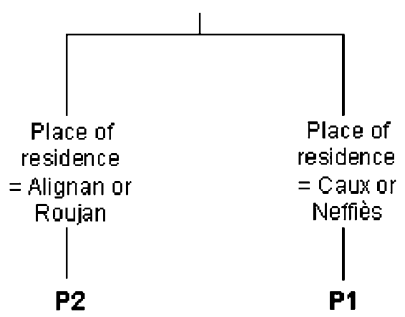

Tree T3

Fig. 4 Presentation of the three selected classification trees. Each tree links the values of an explanatory variable to the label of a majority soil surface management practice (P1 or $\mathrm{P} 2)$. $\mathrm{T} 1$ discriminates between the majority practices according to the class of soil trafficability of the plot; T2, according to the percent of plots with low soil trafficability within the set of all of the farm holding's wide alley plots (Farm LST); and T3, according to the place of residence of the wine grower

\subsection{Independency of the variables}

The results of the test of independence between the variable "place of residence of the wine growers" and the practicetrafficability pairs are summarised in Fig. 5. To reduce the number of possible pairs and allow for the realisation of the test, practices $\mathrm{P} 1$ and $\mathrm{P} 3$ were gathered into a single modality, while high and indeterminate trafficability were gathered into a single class. The figure clearly shows that the two variables were not independent $(p$ value $=2.2 \mathrm{e}-16)$ and that the distribution of practice-trafficability pairs varied according to the place of residence of the wine growers. The most striking result was the significant dominance of a type of practice-trafficability pair in each commune: the pair "P1

Table 4 Soil surface management practice misclassification rates for each of the three selected classification trees

Location of the plots concerned Misclassification rates for tree

\begin{tabular}{llll}
\cline { 2 - 4 } & T1 & T2 & T3 \\
\hline Alignan & 0.47 & 0.15 & 0.13 \\
Caux & 0.25 & 0.15 & 0.14 \\
Neffiès & 0.35 & 0.22 & 0.20 \\
Roujan & 0.62 & 0.51 & 0.21 \\
The whole study site & 0.41 & 0.24 & 0.16 \\
\hline
\end{tabular}

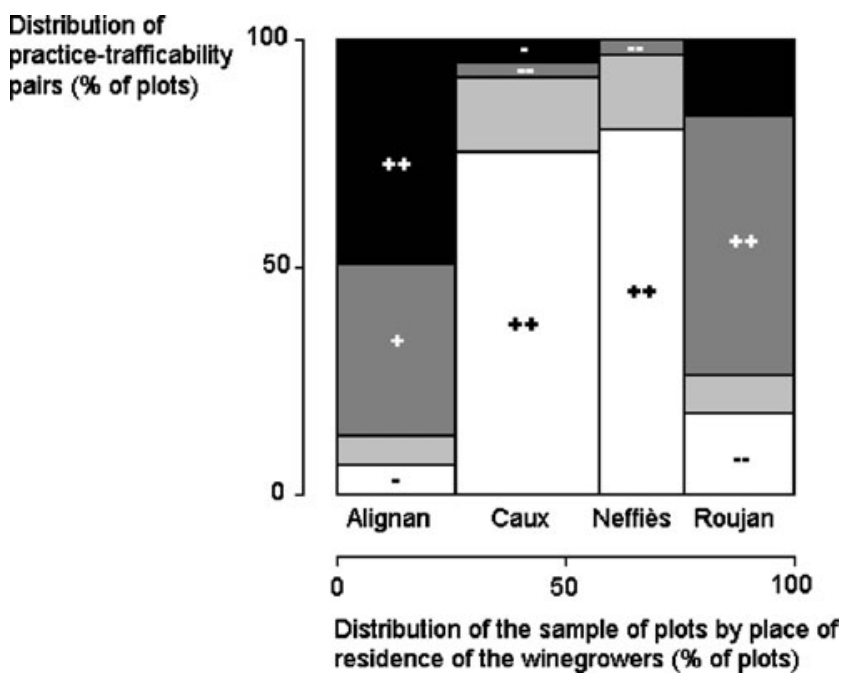

Fig. 5 Distribution of practice-trafficability pairs by place of residence of the vine growers. The pairs of practice-soil trafficability were differentiated by four different colours as follows: white, practices P1 or P3 associated with high or indeterminate trafficability; light grey, practices $\mathrm{P} 1$ or $\mathrm{P} 3$ associated with low trafficability; dark grey, practice P2 associated with high or indeterminate trafficability; and black, practice P2 associated with low trafficability. The independency between the modalities of the two variables was tested by computing the Pearson residuals. A residual greater than +2 indicates a significant positive dependency between two modalities (single plus sign residual> +2 , double plus sign residual $>+4$ ). A residual less than -2 indicates a significant negative dependency (single minus sign residual $<-2$, double minus sign residual $<-4$ ). The strength of the relationships increases with the absolute values of the residuals

or $\mathrm{P} 2$ practices-high or indeterminate soil trafficability" in Caux and Neffiès, the pair "P2-low trafficability" in Alignan and the pair "P2-high or indeterminate soil trafficability" in Roujan. In Roujan, the use of practice P2 was clearly not related to low soil trafficability.

\subsection{Discussion}

\subsubsection{Spatial variability of the relationship between soil trafficability and soil surface management practices}

As expected, the choice between the two dominant practices, P1 and P2, was significantly related to soil trafficability at the plot scale (tree T1) and even more to low trafficability in the wide alley plots of the farm holdings (tree T2). The data seemed to indicate that above the threshold value of $35 \%$ of plots with low trafficability, wine growers applied practice P2 to all of their plots regardless of trafficability, whereas below $35 \%$, practice $\mathrm{P} 1$ was preferentially chosen. These results can be explained by the wine growers' tendency to adopt a predominant practice, as shown in Table 1 . Such a tendency may be related to the fact that crop management choices are often made not at the scale of the individual plot but rather at the scale of plot groups aggregated on the basis of criteria that 
may differ according to individual farmers and their constraints (Aubry et al. 1998). Strong plot constraints can reduce the choice of practices in the concerned plots and lead to homogenisation of practices among farmers at the plot scale, e.g., narrow alleys are associated with P3, as shown in Biarnès et al. (2009). When the plot constraints are weaker, however, farmers have a wider range of options, and this can result in different choices according to holding's constraints or socio-economical environment. To simplify work by limiting the range of different practices used on a farm, a practice selected to resolve a particular problem in a particular plot or set of plots may be used in other plots. For example, such a practice limitation has been found in the application of crop management specifications for horticultural crops in northern France (Le Bail et al. 2006). Another practice limitation exemplified in our study was the use of practice P2, which was not limited to plots characterised by low soil trafficability. The extended use of P2 should be attributed to the comparative advantages of P2, which can be exemplified as follows: compared to intensive integral shallow tillage (based on the use of more than two tillages during the year), P2 may reduce labour time requirements through the use of herbicides (one or two sprayings a year) in some alleys, and compared to integral chemical weeding, P2 benefits from a more environmentally friendly image.

However, the place of residence of the vine grower overdetermined the choice of practice. Two explanations can be given. The first explanation is that the vineyards of the holdings were mainly located within the municipal boundaries of the place of residence of the vine grower (Cramer's $V=0.73$ between the variables "municipality of location of the plot" and "place of residence of the wine grower") and that soil trafficability is not evenly distributed among municipalities, as seen in Fig. 3. The dominance of practice P1 in Caux and Neffiès can be attributed to the weak presence of high and indeterminate soil trafficability in these municipalities, while the dominance of practice P2 in Alignan can be attributed to the dominance of low trafficability. The second explanation is that individual choices may be limited by collective technical norms, which may differ from one municipality to another, reflecting the municipal dimension of dialogue networks in the Peyne Valley. As has been shown by sociologists, social networks play a leading role in the diffusion of practices, structuring the exchange of information among farmers or between farmers and agents of extension services (Darré et al. 1989; Compagnone 2004). For farmers, social networks are places where knowledge is produced. However, they are also places where norms that direct their choices and constrain their options are defined (Conein et al. 2004). Studies have indicated that such professional dialogue networks can have a municipal dimension. In particular, recent studies have shown the role of the municipal dimension in French viticulture in Bourgogne (Compagnone 2004, 2010). In the particular case of the Peyne Valley, a partial description of the dialogue networks of wine growers in Alignan and Caux has shown that technical dialogues principally involve wine growers of the same municipality (Compagnone, unpublished data). Only a few links exist between the wine growers of these two municipalities. Local norms of pest management and soil surface management practices have been identified for each of the two dialogue networks. In Alignan, where the wine growers were more interconnected, the practices were less variable than in Caux, which suggests that the local norms were more constraining. In the Peyne Valley, the following factors may have supported or reinforced the municipal dimension of professional dialogue networks: (1) the presence of municipally based cooperative wineries, which collect the majority of the grape production, or (2) the mode of action of the Chamber of Agriculture, which is a public institution that provides services for farmers. The Chamber of Agriculture plays a major role in the diffusion of environmentally friendly production by creating groups of municipally based wine growers who are trained by a technical adviser from the Chamber of Agriculture. Such a group exists in the municipalities of Alignan, Roujan and Neffiès but not in Caux, where the activities of the chamber are limited. The extended use of P2 in Roujan, regardless of soil trafficability, should be attributed to differences in technical norms among municipalities.

\subsubsection{Performance and limitations of the expert classification of soil trafficability}

In this study, an evaluation of soil trafficability according to expert rules was conducted for each soil unit of a 1:25,000 soil map. In the literature, the classical evaluation of soil trafficability and workability is based on a modelling approach that employs soil and climatic parameters (Rounsevell and Jones 1993). Such an approach requires detailed parameters not directly and easily available at the scale of the 1:25,000 soil map. Consequently, we chose an expert classification that takes into account the interactions among soil properties, their variability and the influence of different pedoclimatic situations. To this end, the expert classification was based on a detailed soil map; classical soil maps (e.g., a 1:100,000 scale), which obscure the high variability of soils such as those found in Mediterranean regions, are not sufficient for such a classification. However, the local variability of soil properties remained, which may have limited the expert classification's performance. The classification key was based on the use of five variables. The values of the variables were assessed using expert knowledge of the main properties of the soil unit (V1, V2, V3 and V5) or the main topographic positions of the plots within the soil unit (V4). Soil properties were considered homogeneous within most of the soil units 
(homogeneous soil units), whereas properties of the deeply tilled layer (V1 and V3) may vary at the plot scale resulting in different soil trafficability levels within a single soil unit. Similarly, the topographic position of a particular plot may not be the dominant position of the soil unit, resulting in different contributing hydrological areas that may also modify soil trafficability.

Moreover, various studies have shown that the manner in which farmers perceive soil characteristics is influenced by their particular context of production or their experience (Cerf et al. 1998). For example, the evaluation of soil trafficability by wine growers may depend on the urgency of the cultivation operations. Consequently, the expert classification of soil trafficability may differ from the wine growers' perception of soil trafficability, which may limit the ability of soil trafficability to explain the choice of soil surface management practices.

Despite these limitations, the expert soil trafficability classification highlighted significant relationships between soil trafficability and soil surface management practices.

\section{Conclusion}

Despite the limitations of an expert classification of trafficability based on the soil units of a 1:25,000 map, our results show that soil trafficability impacted the choice of soil surface management practices in the study area. The two main practices, $\mathrm{P} 1$ and $\mathrm{P} 2$, were significantly related to the trafficability of the plots and even more to the percent of plots with low trafficability within the vineyard of the farm holding. However, the place of residence of the wine growers over-determined the choice of practices because of strong differences in the distribution of soil trafficability classes between municipalities and differences in the technical behaviour of wine growers among different places of residence.

Consequently, although statistically linked to soil surface management practices, soil trafficability is difficult to use as an indicator of the spatial distribution of practices. First, its use to simulate spatial distribution of practices requires knowledge of the spatial distributions of the farm holdings' vineyards, but such data are private and thus difficult to access. Second, on a local level, its use may poorly reproduce the spatial distribution of practices.

Beyond these results, our analysis stressed the need for high-resolution soil maps that cover large areas, which are currently rare; such maps would improve our understanding of the factors that drive the choice of cropping system. Current developments in digital soil mapping (McBratney et al. 2003) will likely provide solutions to fill this gap in the near future. Moreover, by enabling the precise mapping of the variability of soil properties, soil digital mapping might help document the variability of soil trafficability. Our study also highlights the demand for multi-disciplinary analysis that takes into account the complexity of agricultural choices. In particular, we stress the need to better understand how dialogue networks influence farmers' technical choices.

\section{References}

Aubry C, Papy F, Capillon A (1998) Modelling decision-making process for annual crop management. Agr Syst 56:45-65

Barrera-Bassols N, Zinck JA (2003) Ethnopedology: a worldwide view on the soil knowledge of local people. Geoderma 111:171-195

Biarnès A, Bailly JS, Boissieux Y (2009) Identifying indicators of the spatial variation of agricultural practices by a tree partitioning method: the case of weed control practices in a vine growing catchment. Agr Syst 99:105-116

Breiman L, Friedman JH, Olshen RA, Stone CJ (1984) Classification and regression trees. Chapman and Hall, London

Brocca L, Morbidelli R, Melone F, Moramarco T (2007) Soil moisture spatial variability in experimental areas of central Italy. J Hydrol 333:356-373

Cerf M, Papy F, Angevin F (1998) Are farmers expert at identifying workable days for tillage? Agronomie 18:45-59

Compagnone C (2004) Agriculture raisonnée et dynamique de changement en viticulture bourguignonne: Connaissance et relations sociales. Recherches sociologiques 35:103-121

Compagnone C (2010) Influence des dialogues professionnels sur les changements de pratiques des viticulteurs. Le progrès Agricole et viticole 2:34-39

Conein B, Ferrand A, Lazega E (2004) (Eds) Connaissances et relations sociales, Recherches Sociologiques 3

Coulouma G (2008) Carte des sols de la basse vallée de la Peyne. Echellle 1/25000. Notice. UMR Lisah

Coulouma G, Boizard H, Trotoux G, Lagacherie P, Richard G (2006) Effect of deep tillage for vineyard establishment on soil structure: a case study in southern France. Soil Till Res 88:132-143

Darré J-P, Le Guen Y, Lemery B (1989) Changement technique et structure professionnelle locale. Economie rurale 192-193:115-122

Desbiez A, Matthews R, Tripathi B, Ellis-Jones J (2004) Perceptions and assessment of soil fertility by farmers in the mid-hills of Nepal. Agric Ecosyst Environ 103:191-206

Droogers P, Fermont A, Bouma J (1996) Effects of ecological soil management on workability and trafficability of a loamy soil in the Netherlands. Geoderma 73:131-145

Earl R (1997) Prediction of trafficability and workability from soil moisture deficit. Soil Till Res 40:155-168

FAO (1976) A framework for land evaluation. Soil bulletin 32. Food and Agriculture Organization of the United Nation, Rome

Horn H, Fleige H (2003) A method for assessing the impact of load on mechanical stability and on physical properties of soils. Soil Till Res 73:89-99

IUSS Working Group WRB (2006) World reference base for soil resources 2006. World soil resources reports no.103, 2nd edn. FAO, Rome

Lal R (2009) Soils and food sufficiency. A review. Agron Sustain Dev 29:113-133

Le Bail M, Aubry C, Navarrete M, Vaucelle A (2006) Agronomie et qualité dans les filières de production végétale, in: Doré $T, L e$ Bail M, Martin P, Ney B, Roger-Estrade J (eds), L'agronomie aujourd'hui, Quae éditions, Versailles, pp. 285-308

Leenhardt D, Angevin F, Biarnès A, Colbach N, Mignolet V (2010) Describing and locating cropping systems at a regional scale. A review. Agron Sustain Dev 30:131-138 
Louchart X, Voltz M, Andrieux P, Moussa R (2001) Herbicide transport to surface waters at field and watershed scales in a Mediterranean vineyard area. J Environ Qual 30:982-991

Manna P, Basile A, Bonfante A, De Mascellis R, Terribile F (2009) Comparative land evaluation approaches: an itinerary from FAO framework to simulation modelling. Geoderma 150:367378

McBratney AB, Mendoza Santos ML, Minasny B (2003) On digital soil mapping. Geoderma 117:3-52

Mueller L, Schindler U, Mirschel W, Shepherd TG, Ball BC, Helming K, Rogasik J, Eulenstein F, Wiggering H (2010) Assessing the productivity function of soils. A review. Agron Sustain Dev 30:601-614
Paré N, Andrieux P, Louchart X, Biarnès A, Voltz M (2011) Predicting the spatio-temporal dynamic of soil surface characteristics after tillage. Soil Till Res 114:135-145

Paul CL, Devries J (1979) Effect of soil-water status and strength on trafficability. Can J Soil Sci 59:313-324

Ripley B (2007) Tree: classification and regression tree, R package version 1.0-26. http://www.mirrorservice.org/sites/lib.stat.cmu. edu/R/CRAN/doc/packages/tree.pdf. Accessed 12 June 2011

Rounsevell MDA, Jones RJA (1993) A soil and agroclimatic model for estimating machinery work days: the basic model and climatic sensitivity. Soil Till Res 26:179-191

Yun JI (2003) Predicting regional rice production in South Korea using spatial data and crop-growth modelling. Agr Syst 77:23-38 